of this study, it is unlikely that this discrepancy is due to any differences in effect by species, i.e. man or rat. It has been suggested that these antibodies have an insulin-like effect not only on the metabolism of adipocytes but also on liver ${ }^{5)}$ and muscle ${ }^{6)}$ in vitro.

There are several possibilities which may explain this discrepancy. For example, the effect of anti-insulin receptor antibody on the target cells by chronic exposure in vivo may be different from that of this antibody by acute exposure in vitro. To investigate this possibility, Karlsson et al studied the chronic effects of anti-insulin receptor antibody on the metabolism of an adipocyte-like cell line, the 3T3-L1 fatty fibroblasts. They found the condition of insulin desensitization of 3T3-L1 fibroblasts by the chronic exposure to anti-insulin receptor antibody ${ }^{7}$. This insulin resistnat state is very similar to the clinical picture observed in patient with these antibodies. But the precism mechanism of this insulin desensitization is not resolved and remain to be disclosed in the future.

\section{REFERENCES}

1) Kibata, M, K Hiramatsu, Y Fuchimoto, M Sasaki, M Shimono, K Miyake, JS Flier, and GR Kahn, Proc Symp Chem Physiol Pathol (Jap) 15: 58, 1975.

2) Kawanishi, K, K Kawamura, Y Nishina, A Goto, S Okada, T Ishida, T Ofuji, GR Kahn and JS Flier, J Clin Endocrinol Metab 44: 15, 1977.

3) Kasuga, M, Y Akanuma, T Tsushima, K Suzuki, K Kosaka, and M Kibata, J Clin Endocrinol Metab $47: 66,1978$.

4) Kasuga, M, Y Akanuma, T Tsushima, $Y$ Iwamoto, $\mathrm{K}$ Kosaka, $\mathrm{M}$ Kibata and $\mathrm{K}$ Kawanishi, Diabetes 27 : 938, 1978.

5) Lawrence, JC Jr, J Larner, CR Kahn, and J Roth, Mol Cell Biochem 22: 153, 1978.

6) LeMarchard-Brustel, Y, P Gorden, JS Flier, CR Kahn, and P Freychet, Diabetologia 14: $311,1978$.

7) Karlsson, FA, E Van Obberghen, G Grunfeld, and GR Kahn, Proc Natl Acad Sci USA 76 : $809,1979$.

\title{
(3) Autoantibodies Against TSH-Receptor in Graves' Disease
}

\author{
Yoshimasa SHIShiba, MD \\ Division of Endocrinology, Department of Medicine, Toranomon Hospital \\ Akasaka, Tokyo 105 Japan
}

\section{Introduction}

As is widely accepted, autoantibodies in patients with Graves' disease are capable of binding to TSH-receptor, stimulating thyroid tissue, and also being inactivated by human thyroid extract. Although the species-specificity of the antibody is well known $^{1)}$, it remains uncertain whether the capability of the IgG of binding to human TSH-receptor is rather specific or common to TSH-receptor of other animal species.
By comparing the capability of the IgG's of the binding to TSH-receptor, thyroid stimulation and that of being inactivated thyroid tissue of human and mouse, we sought to determine whether the antigen to cause those autoantibodies is solely TSHreceptor or not.

II. Species-specificity of the binding of IgG's to TSH-receptor

To examine whether TSH-displacing activities of the IgG of Graves' disease is 


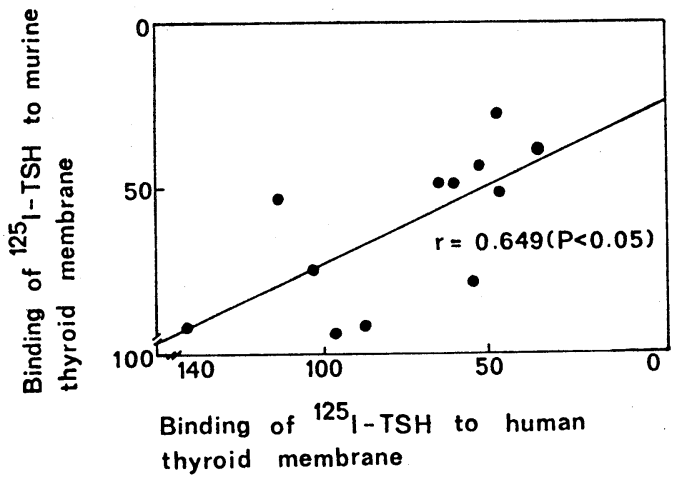

Fig. 1. Comparison of TSH-receptor binding inhibition by Graves' lgG's in human and murine thyroid gland

specific to human thyroid TSH-receptor, we examined the IgG's TSH-displacing activity employing murine thyroid TSHreceptor. Pure bovine TSH was iodinated with peroxidase method and was purified with crude thyroid membrane fraction as described by Ozawa et $\mathrm{al}^{2)}$. The TSHdisplacing activity measured with murine thyroid was compared with that measured with human thyroid tissue. Both TSHdisplacing activities correlate each other $(\mathrm{r}=0.65)$, indicating that the binding of IgG's to TSH-receptor is not so speciesspecific (Fig. 1A).

Then we examined whether TSH-displacing activities of the IgG measured with murine thyroid is correlate with the thyroidstimulating activity measured as LATS. As shown in Fig. 1B, both activities correlate each other, indicating that binding to TSH-receptor may be a pre-requisite step for the stimulation.

If TSH-receptor is a sole antigen to cause antibodies capable of receptor binding and stimulation, those activities should be inactivated by human as well as murine thyroid tissue. Murine thyroid stimulating activity (LATS) is inactivated by human thyroid tissue but only partially by a large dose of murine thyroid extract (3). Thus, the result is compatible with the thought that the receptor is not a sole antigen to cause those antibodies.

\section{TSH-receptor and LATS-inactivator}

If LATS is capable of stimulating thyroid tissue by binding to TSH-receptor, it is expected that TSH-receptor is the sole antigen to cause LATS. To examine this possibility, LAA (LATS-absorbing-activity) was extracted from human thyroid tissue. From the LAA fraction, intact TSH-receptor was removed by TSH-coupled affinity chromatography. Glycoprotein component of the fraction was also removed by Con A coupled affinity chromatography. After those manipulations, LATS-inactivating ability of the LAA was measured by in cubating standard LATS with pretreated LAA. LATS activity was estimated with our in-vitro method in which $\mathrm{T}_{3}$ release from incubated murine thyroid tissue was measured with radioimmunoassay ${ }^{4}$. LATS-inactivating ability was only partially reduced by the pretreatment with TSH-affinity column but to a considerable extent by Con A-column (Fig. 2). This result indicates that glycoprotein component Partial inhibition of the ability to neutralize LATS by TSH affinity colum indicates that integrated structure of the TSH-receptor is not required for the neutralization binding (Fig. 2).

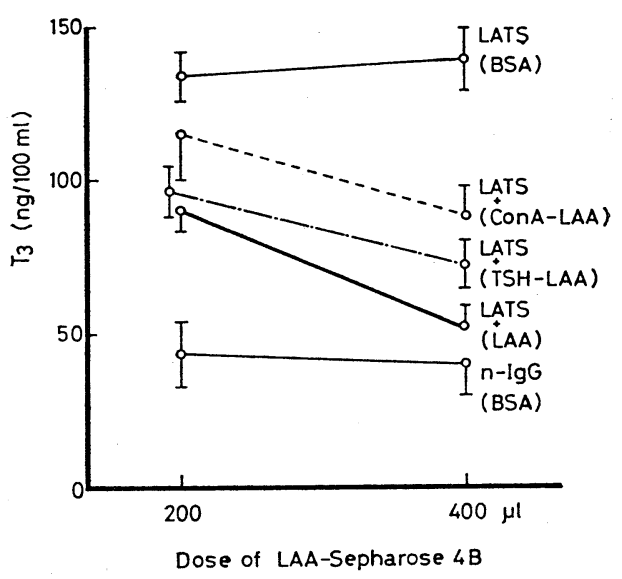

Fig. 2. Inhibition of LATS by LAA treated with Con A- or TSH-Sepharose 4B 
IV. Immunoprecipitation of solubilized TSH-receptor-antibody complex

It was recently reported by Smith that IgG can displace labelled TSH from solubilized receptor as well as from membraneassociated receptor. The magnitude of displacement was almost the same in those two different analysis ${ }^{5)}$. In the present study, we tried to solubilize ${ }^{125} \mathrm{I}-\mathrm{TSH}$ receptor-antibody complex by $0.5 \%$ Triton $\mathrm{X}-100$, the latter was shown to solubilize membrane associated protein and enzyme but not to dissociate antigen-antibody complex. ${ }^{125} \mathrm{I}-\mathrm{TSH}$ binding or inhibition of binding was determined by incubating membrane associated TSH-receptor, Graves' IgG and ${ }^{125} \mathrm{I}$-TSH for $60 \mathrm{~min}$. After completion of the reaction, $\mathrm{B} / \mathrm{F}$ of ${ }^{125} \mathrm{I}-\mathrm{TSH}$ was separated with centrifugation at $15000 \mathrm{~g}$ for $15 \mathrm{~min}$. The precipitated radioactivity was counted. The results is an indicator of labelled TSH
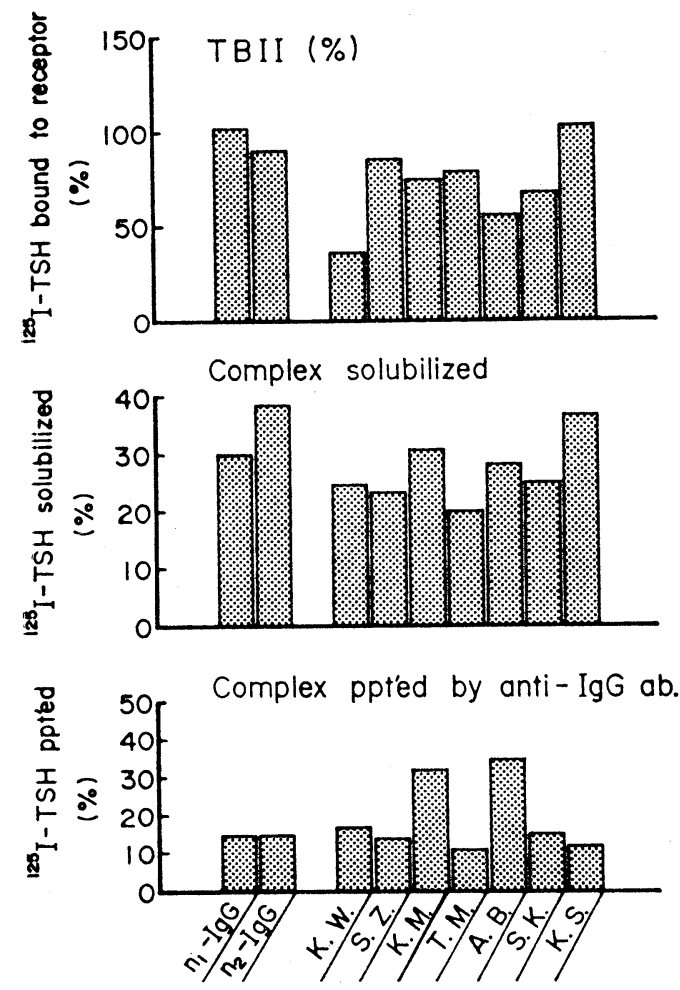

Fig. 3. Immunoprecipitation of TSH-receptor-antibody complex solubilized by detergents. displacement from the receptor by IgG's (Top panel in Fig. 3). Triton X-100 was added to the precipitate at the final concentration of $0.5 \%$, stirred and centrifuged again. Radioactivity of the supernatant was tested for the presence of ${ }^{125} \mathrm{I}-\mathrm{TSH}$ receptor complex by polyethylene-glycole precipitation. Approximately 30\% of the radioactivity was solubilized by the detergent and almost all of the solubilized radioactivity was precipitated with 6\% polyethylene-glycole, indicating that the solubilized radioactivity is the ${ }^{125} \mathrm{I}-\mathrm{TSH}$ receptor complex containing attached antibody IgG. When large amount of antihuman IgG antibody of the rabbit was added to the supernatant, $10-14 \%$ of the radioactivity was precipitated in 7 among 9 occasions examined. However, in two occasions, anti-human IgG antibody preci pitated as much as 35\% radioactivity (Fig 3 , bottom panel). From this results, it was speculated that the amount of IgG attached to TSH-receptor varied widely and that the site of binding of IgG to the receptor may be heterogenous.

\section{Alteration of autoantibody activities during the course of the thyrotoxicosis}

In a previous publication, we disclosed that human thyroid stimulating activity estimated by multiple indicators such as adenyl cyclase activity, cAMP levels and $\mathrm{T}_{3}$-release from the thyroid tissue is closely related to LATS-protector activity instead of LATS activity. Thus, in human, IgG's TSH-receptor binding may not be related to the mechanism of stimulation. The LATS-protector activity disappears either rapidly after subtotal thyroidectomy or slowly during the thionamide medication ${ }^{6)}$. When the patient became euthyroid, LATS-protector or HTS (measured by human thyroidal cAMP increase in $120 \mathrm{~min}$ ) was no more detected, irrespective of the result of thyroid suppression test. This result would indicate that thyrotoxic state itself may enhance the production of antibody. The euthyroid 
state, obtained by the treatment, in turn, inhibits the production of autoantibodies by a mechanism still remaining unknown.

\section{Summary and conclusion}

Although autoantibody against TSHreceptor is good candidate as a pathogenomonic factor to cause hyperthyroidism, there exist diversities in various aspects.

First, the site of binding of the IgG may not be identical to that of TSH-binding. Second, binding of IgG to the receptor may or may not trigger thyroidal stimulation. The third, all the available measure of human thyroid stimulation is not sensitive enough to allow a reproducible and meaningful study. Thus, to verify the hypothesis that autoantibody against TSH-receptor is truely a cause of hyperthyroidism of Graves' disease, these aspects have to be clarified.

\section{REFERENCES}

1) a. Adames, DD, and TH Kennedy, Evidince to suggest that LATS protector stimulates the human thyroid, J Clin Endocrinol Metab. 33 : 47, 1971.

1) b. Shishiba, Y, T Shimizu, S Yoshimura, and $\mathrm{K}$ Shizume, Direct evidence for human thyroid thyroid stimulation by LATS protector, J Clin Endocrinol Metab 36: 517, 1973.

2) Ozawa, Y, RMB Maciel, IJ Chopra, DH Solomon, and GN Beall, Relationship among immunoglobulin markers in Graves' disease, J Clin Endocrinol Metab 48(3) : 381, 1979.

3) Shishiba, Y, T Shimizu, S Yoshimura, and $\mathrm{K}$ Shizume, Discrepancy between inactivation by thyroidal particulate fraction and thyroid stimulating activity of long-acting thyroid stimulator (LATS), J Glin Endocr 34: 7, 1972.

4) Chatterjee, S, M Takaishi, T Shimizu, and $\mathrm{Y}$ Shishiba, Characterization of $\mathrm{T}_{3}$ immunoreactivity release from thyroid gland in vitro : a reflection of colloid droplet formation, Acta Endocrinologica 86: 119, 1977.

5) Smith, BR, S Karem, VB Petersen A Brennan, and $\mathrm{R}$ Hall, Multiple forms of hormone receptor complex, Abstruct 777: VI International Congress Endocrinology, 1980.

\title{
(4) The Role of Angiotensin Receptors in Blood Pressure Regulation
}

\author{
Soitsu Fukuchi, MD \\ Department of Internal Medicine, Fukushima Medical College
}

Angiotensin II plays an important role in maintenance of extracellular fluid volume and blood pressure by binding to receptor in the arterial walls, the adrenal cortex and the kidneys. Recently, renin was also found in the brain, but it remains now obscure that the brain renin generates angiotensin to act upon central nervous system to regulate blood pressure. In this report, regional distribution and extent of specific angiotensin II receptor in the brain of spontaneous hypertensive rat were

Jap J Med Vol 20, No 1 (Jan 1981) estimated by means of a radioligend receptor assay of angiotensin II, and relationship between changes in binding activity of the receptor for angiotensin II and development of hypertension was further studied. The angiotensin II receptors in the vascular smooth muscle, the adrenal gland and the renal glomerulus were examined in rate with various kinds of experimental hypertension and in patients with hypertension or abnormalities in renin-angiotensin system. 